\title{
Fashioning a Search Engine to Support Humanities Research
}

\author{
Frank Wm. Tompa \\ David R. Cheriton School of Computer Science \\ University of Waterloo \\ Waterloo, ON, Canada \\ fwtompa@uwaterloo.ca
}

\begin{abstract}
Scholarship in the humanities often requires the ability to search curated electronic corpora and to display search results in a variety of formats. Challenges that need to be addressed include transforming the texts into a suitable form, typically XML, and catering to the scholars' search and display needs. We describe our experience in creating such a search and display facility.
\end{abstract}

\section{CCS CONCEPTS}

- Applied computing $\rightarrow$ Document searching; Extensible Markup Language $(X M L)$; ・ Information systems $\rightarrow$ Digital libraries and archives;

\section{KEYWORDS}

Document markup, text tagging, digital humanities, historical philosophy, literary criticism, Albertus Magnus, Latin orthography, style sheet

\section{ACM Reference Format:}

Frank Wm. Tompa. 2018. Fashioning a Search Engine to Support Humanities Research. In DocEng '18: ACM Symposium on Document Engineering 2018, August 28-31, 2018, Halifax, NS, Canada. ACM, New York, NY, USA, 10 pages. https://doi.org/10.1145/3209280.3209520

\section{BACKGROUND AND MOTIVATION}

Many researchers in the humanities have turned to computers to help them to examine documents. Most often the goal is to understand the thoughts and reasoning of those documents' authors, but it may also be to understand an author's craft in creating the documents under investigation or to gain insight into the author's life and times. Researchers who study document collections may come from a variety of backgrounds, leading the Society for Textual Scholarship to welcome "scholars from disciplines such as literature (in all languages), history, musicology, classical and biblical studies, philosophy, art history, legal history, history of science and technology, computer science, library science, lexicography, epigraphy, paleography, codicology, cinema studies, theatre, linguistics, and textual and literary theory." Digital humanities research might

\footnotetext{
${ }^{1}$ https://textualsociety.org/

Permission to make digital or hard copies of all or part of this work for personal or classroom use is granted without fee provided that copies are not made or distributed for profit or commercial advantage and that copies bear this notice and the full citation on the first page. Copyrights for components of this work owned by others than ACM must be honored. Abstracting with credit is permitted. To copy otherwise, or republish, to post on servers or to redistribute to lists, requires prior specific permission and/or a fee. Request permissions from permissions@acm.org.

DocEng '18, August 28-31, 2018, Halifax, NS, Canada

(C) 2018 Association for Computing Machinery.

ACM ISBN 978-1-4503-5769-2/18/08 . \$ \$15.00

https://doi.org/10.1145/3209280.3209520
}

require computationally advanced analyses $[1,2]$, but often the sheer volume of a corpus under study makes it necessary (or at least advantageous) to digitize documents of interest and to make them available through a search engine that is effective in finding passages of interest to the scholar throughout the research period [31].

Conventional search engines, however, are not designed to meet the needs of scholars from the humanities. For example, scholars usually want to find passages that exactly match their queries, rather than being satisfied with ranked lists of documents or document fragments that are judged to be relevant in response to a few keywords. When approximate matches are sought, scholars usually require that the form of approximation be carefully controlled to reflect normalization in spelling rather than semantic equivalence. Furthermore, a scholar's corpus is often not freely available to the general public: it may include intellectual property that must be protected, and a document management system must therefore ensure that the documents are not unintentionally disseminated.

This paper describes the components of a search system developed for the Alberti Magni e-corpus, the texts digitized in a project undertaken to study the philosophical ideas discernable from the collected works of Albertus Magnus, ${ }^{2}$ a prolific and influential 13thcentury philosopher and theologian [27]. Those works form an authoritative reference on Christian theology, philosophy, and natural science as it was understood in the Middle Ages. The Latin texts span a wide variety of subjects, including "logic, ethics, political philosophy, philosophy of nature, philosophical psychology, zoology, botany, mineralogy, geography, astronomy, meteorology, mathematics, metaphysics, systematic theology, interpretation of Scripture" [32]. The 60 texts comprising the Alberti Magni e-corpus range from short letters, such as Testamentum Domini Alberti, without any structure other than page boundaries, to long commentaries on other texts, including Super IV libros Sententiarum, a commentary on Peter Lombard's theological tome, in which the extensive commentary follows the structure of Lombard's work (a prologue followed by four books, each book-Liber-divided into sections, each designated as distinctio) and is interspersed with Lombard's text, as described by the simplified grammar in Figure 1. Only the text written by Albertus Magnus should be searchable; the text being commented upon (i.e., the Lombard substructures in Figure 1) serves to anchor the commentary, but it is not to be searched and yet it is to be displayed when browsing.

The code base for the custom-developed search engine was adapted from that used to support the Electronic Campsey Project, ${ }^{3}$ which in turn was modelled on the software developed earlier to

\footnotetext{
${ }^{2}$ http://albertusmagnus.uwaterloo.ca/

${ }^{3}$ http://margot.uwaterloo.ca/campsey/cmphome_e.html
} 


$$
\begin{array}{lll}
\text { opus } & := & \text { preface Lombard prolExpl liber+ } \\
\text { liber } & := & \text { title? prologue? distinctio+ } \\
\text { distinctio } & := & \text { title? commentary+ } \\
\text { commentary } & := & \text { Lombard (expositio } \mid \text { divisio } \mid \text { divEtExp)? } \\
& & \quad \text { articulus* (expositio } \mid \text { divisio)? articulus* } \\
\text { articulus } & := & \text { title text }
\end{array}
$$

Figure 1: Nesting structure of Albertus Magnus's Super IV libros Sententiarum; all undefined non-terminals represent running text, typically divided into paragraphs and sentences and interleaved by page and column breaks

search the Oxford English Dictionary (OED) and display the results [30].

This paper summarizes the approach taken to develop an engine for searching collections of texts, based on the needs of the Alberti Magni e-corpus project. Section 2 describes the conventions used to mark up the text as part of the proof-reading and correction effort that follows initial optical character recognition. Next, Section 3 describes the challenges encountered when converting the markedup text to XML in preparation for search and display. Section 4 describes the functionality of the search engine, and Section 5 describes the text formatter that displays document fragments by replacing XML tags with HTML codes and suppressing XML fields, as desired. Finally, Section 6 summarizes some lessons learned and outlines areas for further research and development.

\section{INITIAL TEXT MARKUP}

A scholar in the humanities, having chosen the texts to analyze, often begins by mechanically scanning myriads of printed document pages, applying optical character recognition (OCR), and laboriously correcting errors (by comparing the output against the original images, perhaps aided by a language-specific spelling checker). This digitization process results in a stream of text, with some typography and layout preserved.

Successful text search and display requires that structural units and features within a document are recognized by the search engine. This typically includes the recognition of layout structure (pages and columns), logical structure (chapters, sections, paragraphs, and sentences), and embedded features (headings, italic text, Hebrew text, and illustrations). All documents in the editions scanned for the Alberti Magni e-corpus are laid out on pages, but only some place the text into columns. All have sentences and paragraphs, and many are hierarchically arranged in units designated as LIBER (book), TRACTATUS (tract), and CAPUT (chapter).

During the proof-reading stage, some initial markup to capture the structural units and features can also be added to the text. OCR software captures not only the sequence of letters that comprise a text, but also its spacing and typography, and thus some of this markup may be derivable from a parallel analysis of the physical layout of the scanned pages [23]. Beyond what the OCR system provides, some structural markup is simple to insert manually. Unfortunately, there is a cost to adding markup by hand: the more markup that is required, the greater the additional cognitive burden that is placed on the proof reader and the greater the time to insert markup by hand [18]. For the Alberti Magni e-corpus, the following markup conventions were designed to balance completeness and simplicity:

- enclose all page and column numbers within slashes (e.g., /24/ for the start of page 24, /135B/ for the start of the second column on page 135);

- insert \$err\#corr\$ to indicate that the erroneous text in the original manuscript err has been corrected to corr;

- surround transliterations of Greek letters with [GREEK: and ]; and similarly surround transliterations of Hebrew letters with [HEBREW: and ];

- indicate the presence of graphics by the notation [ILLUSTRATION];

- identify source text upon which Albertus Magnus is commenting by inserting [@author:] at the start and [@] at the end, where author is the name of the source text's author;

- surround tables with $\mid$ - at the start of each table's first line and - | at the end of each table's last line, and insert | between table columns on each line;

- where non-standard section headings are used, supplement them with synthetic headings in a standardized form; for example, to indicate that the heading Cuius primus tractatus est de homine indicates the start of the first "tractatus", which is entitled "De homine", the scholar inserts the mark up:

+TRACTATUS I\%DE HOMINE+Cuius primus tractatus est de homine

The resulting documents have sufficient structure explicitly and unambiguously marked that it can be converted into well-formed XML that includes tags marking all textual elements of interest to the researcher. However, the ability to transform a document collection into XML in theory does not imply that it is straightforward to perform the transduction in practice.

\section{RECOGNIZING TEXT STRUCTURE}

Before new texts are added to the e-corpus, they need to be converted to XML, often built upon the TEI tag set developed by the Text Encoding Initiative [7, 29]. The Alberti Magni e-corpus requires tags that mark pages, columns, titles, structural sections, paragraphs, sentences, hierarchical locations that serve as targets for citations into the text, and various other features present in the corpus. Rather than building individual taggers for each document, a single conversion pipeline was designed to be applied to all of the works in the e-corpus; in this way, as conversion errors are found, the tagging pipeline can be corrected and reapplied to all documents to ensure that similar, but undetected, errors in documents already processed are also corrected.

For the Alberti magni e-corpus, the input text is stored in rich text format (RTF), using predetermined markup conventions as described in the previous section. The texts are first converted to HTML using rtf2html. ${ }^{4}$ Thereafter the text passes through a series of perl scripts, the first of which removes superfluous white space and HTML encoding (but preserving italics and bold tags). Next, simple atomic elements are tagged: Greek, Hebrew, and illustration indicators are replaced by tags; table delimiters are replaced by corresponding HTML table, row, and cell tags; page and column markers are replaced by empty "milestone" tags with attributes encoding the page and column numbers; and editorial corrections marked as \$err\#corr\$ are changed to <corr $\mathrm{w}=$ "err" $>$ corr $<$ /corr $>$.

${ }^{4}$ https://sourceforge.net/projects/rtf2html/ 
These changes appear to be straightforward, and it is fairly simple to implement a converter that handles the vast majority of the text correctly. However, complications arise when the various markup conventions overlap in the text or occur in unanticipated contexts. The remainder of this section illustrates some of the complications encountered when recognizing the structure found in the Alberti Magni e-corpus.

Page layout conventions are such that page and column boundaries are usually placed where there is white space in a text. However, they can also occur in the middle of words. In order to recognize a complete word that crosses a page or column boundary and still record exactly where the word is split, an element is introduced to mark the starting fragment of a broken word, with an attribute encoding the whole word, and a second element is introduced to mark the second fragment of the word. Thus, for example, the tags in $<$ frag w="sicut" $>$ sic $</$ frag $><$ col $n=" 16 b " /><$ cont $>$ ut $</$ cont $>$ record where the word sicut breaks between the bottom of the first column on page 16 and the top of the next. To complicate things further, a page or column break can also occur in the middle of a correction: \$con/488A/trariuum\#con/488A/trarium\$; thus conversion code must be carefully written to accommodate this variant. Furthermore, if a page or column break is surrounded by italic text, the slashes around the page or column number may well also be in italics: these four variants are indistinguishable by a proof-reader of the text in printed form. Again, conversion code must be able to handle all these variants.

Inserting tags that reflect the collected works' structures requires significantly more attention. The starts of sections are often clearly indicated by key words or phrases at the start of input lines (especially if supplemented by synthetic section headers as described in the previous section), and these markers are often followed by section numbers, but there is sufficient variety to make this task non-trivial. There are 23 markers signifying the start of various types of numbered sections (see Figure 2), and a variety of numbering conventions are used. For example, some structures use Roman numerals (e.g., CAPUT IV.) and other use Arabic numerals (e.g., Sermo 39); the work Sermones parisienses is divided into numbered sections without preceding key words (e.g., I, II), and Determinatio Magistri Alberti de novo spiritu is similarly divided, but using Arabic numerals (e.g., 1, 2), further complicated by the presence of a section numbered $1 \mathrm{a}$ between the section numbered 1 and the section numbered 2; and some sections containing Biblical commentary are numbered by ranges of the verses referenced (e.g., Versus 43-44). In addition, recognizing the starts of structures is further complicated by the possible occurrence of corrections for the structure name, the section number, or both ("\$ACTICULUS\#ARTICULUS\$ XV." vs. “ARTICULUS \$XI.\#IX.\$” vs. "\$ARTICULUS\#ARTICULUS III.\$”).

Having recognized a section heading, any text following it without an intervening blank line is tagged as a title for that section. Text following a blank line is then interpreted as the body of the section, consisting of paragraphs with nested sentences. Because paragraphs are separated by blank lines in the input, marking paragraph boundaries is straightforward. A naïve approach to marking sentence boundaries was adopted, based simply on punctuation

\footnotetext{
${ }^{5}$ All examples in this section are present in the input texts and were discovered while developing the conversion pipeline.
}

$\begin{array}{lll}\text { division } & \text { opening } & \text { nesting } \\ \text { d:liber } & \text { LIBER } & \text { >d:caput } \\ \text { d:tract } & \text { TRACTATUS } & \\ \text { d:caput } & \text { CAPUT } & \\ \text { d:caput } & \text { Capitulum } & \\ \text { d:caput } & \text { CAPITULUM } & \\ \text { d:caput } & \text { CAP. } & \\ \text { d:caput } & \text { Caput } & \text { >d:in-prooem } \\ \text { d:in-caput } & \text { IN CAPUT } & \\ \text { d:in-caput } & \text { In Caput } & \\ \text { d:dist } & \text { DISTINCTIO } & \text {-d:art } \\ \text { d:Lombard } & \text { [Pierre Lombard:] } & \\ \text { d:art } & \text { ARTICULUS } & \\ \text { d:pars } & \text { PARS } & \\ \text { d:qi } & \text { QUAESTIO INCIDENS } & \text { leaf } \\ \text { d:quaes } & \text { QUAESTIO } & \\ \text { d:mem } & \text { MEMBRUM } & \\ \text { d:part } & \text { PARTICULA } & \\ \text { d:subpart } & \text { SUBPARTICULA } & \\ \text { d:quaesit } & \text { QUAESITUM } & \text { leaf } \\ \text { d:ver } & \text { VERSUS } & \text { leaf } \\ \text { d:sermo } & \text { Sermo } & \text { leaf } \\ \text { d:signum } & \text { } & \text { leaf } \\ \text { d:num } & & \text { leaf } \\ & & \end{array}$

Figure 2: Indicators for starts of numbered sections

followed by a capitalized word, but more sophisticated methods could be applied if it were found to be necessary [19].

The end of a section is implicitly indicated by the start of some other section that cannot be nested within it. For example, consider the works with sections marked LIBER and nested sections marked TRACTATUS, which in turn have nested sections marked CAPUT: each LIBER section ends when the next section marked LIBER is encountered; similarly, a section marked TRACTATUS ends when a section marked either LIBER or TRACTATUS begins. However, the structure is not necessarily this regular: LIBER I in the work Topica starts with two CAPUT sections before the first TRACTATUS with its nested CAPUT sections begins; several works have TRACTATUS and CAPUT sections, without first being divided into LIBER sections; all the LIBER sections in the work Politica are divided into CAPUT sections without any divisions marked TRACTATUS. Many other works use radically different structures and substructures, as indicated in Section 1 above, making it important to characterize the constraints on the nesting of structures. Figure 2 lists all the structural divisions in the e-corpus that correspond to (usually) numbered sections, together with the possible text sequences that occur before the section number appears. The third column indicates constraints on the nesting of those divisions, as follows:

$\begin{array}{ll}\text { leaf } & \text { no nested substructures } \\ >\text { struc } & \text { disallowed in struc } \\ \text {-struc } & \text { no nested substructures and disallowed in struc }\end{array}$

There are 23 additional rules for those substructures (such as prologues, sections marked EXPOSITIO TEXTUS, etc.) that are never numbered. Using these tables, the ends of structures are recognized much like a shift-reduce parser processes context free languages [9]. 
Peri hermeneias (ed. Borgnet, 1890), Lib.II, tract.1, cap.13, p.92a Topica (ed. Borgnet, 1890), Lib.l, cap.2, p.45a

De animalibus (ed. Stadler, 1916-1920), Lib.XXIII, cap.2, p.504

De fato (ed. Mandonnet, 1927), art.1, p.399

Super lob (ed. Weiß, 1904), cap.13, v.28, p.179

Super leremiam (frag.) (ed. Meersseman, 1932), in cap.1, v.5, p.7

Super Threnos (ed. Borgnet, 1893), praefatio, p.246a

Super prophetas minores (ed. Borgnet, 1892), Amos, prol., p.181

De IV coaequaevis (ed. Borgnet, 1895), tract.4, q.61, art.2,

part.1, quaesit.2, p.203b

Super IV libros Sententiarum (ed. Borgnet, 1893-4), Lib.IV, dist.27, A-B, divisio et expositio textus, p.250b

Summa theologiae (ed. Borgnet, 1894-1895), Pars II, tract.1, q.4, m.2, art.5, part.3, q.inc.1, p.103b

Determinatio Magistri Alberti de novo spiritu (ed. de Guibert, 1931), 1-a, p.117

Epistula de ungelt (ed. Rieder, 1901), p.47

\section{Figure 3: Examples of labels to identify match locations}

The last major challenge to address when recognizing structure is to place markers that can help to identify the locations of matches found by the search engine. For each work, the specifications of how to present each match are determined by the needs of the scholars, as illustrated in Figure 3 with examples from the Alberti Magni e-corpus.

Because each work is stored and searched in a separate file, the search engine can extract the name of a work, including the editor and year, from a "metadata" table associating that name with the file name. The remainder of the location information for a match needs to be determined primarily from the nesting of structures surrounding the match point in the text.

Unfortunately, there are two pieces of the location information that are associated with non-nested structures: (1) both page and column numbers are stored as milestones rather than via nesting, and (2) commentary on Lombard's text in Super IV libros Sententiarum refers to the previous one or more sections of that text that do not have their own separate commentary. Thus, in Figure 3, the location within Super IV libros Sententiarum refers to the second column on page 250, within the section marked Divisio et Expositio Textus (divEtExp in Figure 1) that follows sections A and B of Lombard's text, found within the $27^{\text {th }}$ distinction within Liber IV. With these rules, and a table mapping XML structured division names to the abbreviations (e.g., d: liber to "Lib.", $d$ :mem to "m."), an attribute value capturing the complete location information (except the name of the work) can be inserted into each section start tag and into each page and column milestone in the corpus. The detailed location information for a search match is then set to the last location attribute value that precedes the match point, prepending it with the information found in the metadata table.

\section{CORPUS SEARCHING}

The original $O E D$ search engine was driven by queries expressed using the PAT region algebra [10,28]. At 570MB, the OED e-corpus was very large for its time, requiring its search engine to use a "suffix array" index to achieve reasonable performance [11]. The format chosen for text display was specified by style sheets using LECTOR [26], and the resulting display commands were executed on the X Window System (X11). More recently, the OED search software was revised to run as a web application, replacing РАT by the Wumpus [3] search engine, which also uses a region algebra to specify searches. At the same time, Lector was replaced by DrAGomAn a simple, but similar, XML-to-HTML converter driven by style sheets (as described in Section 5).

The Alberti Magni e-corpus is an extensive text collection, but its size remains modest for search engines running on today's hardware:

\section{0 works 18,974 pages 9.07 million words $\quad 130 \mathrm{MB}$}

As a result, a simple main memory search system is sufficiently powerful to provide suitable functionality without the inconvenience of indexing. The sgrep "structured grep" utility [14] is designed to search XML-like text without relying on an index, and it is thus highly suitable as a backbone for a search engine in this context.

The combined search and display code is invoked from a web page that uses a front-end handler to read parameters for the search, calls a back-end search engine (here, sgrep), formats the results (using Dragoman), and presents the results on a subsequent web page that provides a form for specifying the next query. The code depends on several configuration files that are referenced from a single "directory file" read at compile time by the front-end handler. This directory file specifies the location of the metadata table (which stores the names and locations of files to be searched), the commands required to invoke the search engine, the location of the style sheets for controlling how to display search results, the location of the list of searchable units (e.g., paragraphs, pages, sections), and the location of a file containing messages to be displayed by the front end. Because the metadata table, list of style sheets, list of searchable units, and list of messages are all referenced indirectly, their contents can be changed as desired without recompilation.

Given a query, the sgrep system (like PAT and Wumpus) returns matching regions rather than searching for documents that contain similar words, where a region can be any contiguous sequence of one or more characters within the document being searched. The system finds all text regions that match a query exactly, returning either the number of such regions or the extents themselves (as pairs of offsets for the start and end of each region or as strings of characters found between those offset pairs). The sgrep query language is a "region algebra" [5] that treats string queries as searches for regions whose contents exactly match the query string; includes operators for testing for region inclusion, adjacency, and proximity; and includes operators for combining lists of regions through conjunction, disjunction, and negation.

The reliance on matching regions leads to some surprising results for users familiar with the word-based retrieval engines commonly used to search the web. For example, a search for the string et in Albertus's Mineralia matches 4788 two-character regions that contain the string et, only 3026 of which are instances of the word et. A search for " et " (the word surrounded by blanks) identifies 2906 instances of the word, but other instances are abutted by punctuation marks or XML tags. If the goal is to find all instances of the word "et," the solution is to provide an option to find all regions that correspond to maximal contiguous sequences of letters and 
returning those that coincide with the regions matching the string et after case-folding. As a second surprising example, a search for regions matching in ipsum returns 4 matches of the phrase in Albertus's Mineralia, but it misses the instance on page 10 where the two words are separated by a column break. A somewhat acceptable solution to searching for the phrase consisting of these two words is to find all sentences that contain the string in followed a blank followed (eventually) by the string ipsum within that same sentence; unfortunately this returns 39 spurious matches that include other intervening words as well. As a consequence, the results returned when searching for phrases must be carefully examined.

Importantly, sgrep also supports the formation of regions that extend from a region in one list until the nearest region in another list. For example,

$$
\text { define(UNIT_STAG,( "<d:" .. ">" )) }
$$

first creates a region list $L_{1}$ of all regions (of length 3) matching the string " $<\mathrm{d}$ :" and a second list $L_{2}$ of all single-character regions that contain " $>$ ", then forms regions from the start of each region $x \in L_{1}$ to the end of each region $y \in L_{2}$ where there does not exist $z \in L_{1} \cup L_{2}$ such that $z \neq x, z \neq y$, and $z$ falls within the region extending from the start of $x$ to the end of $y$. That is, the list of regions defined by UNIT_STAG above includes each region defined by the closest pairs of " $<\mathrm{d}$ :" and ">", inclusive of both ends. Instead of ". .", the notation ".." includes the start regions but excludes the end regions, ".." excludes the start regions and includes the end regions, and "-_" excludes both the start and end regions from the returned regions list (i.e., the returned regions extend from the ends of the first regions to the starts of the second paired regions).

To use sgrep, it is necessary to describe the encoding of structures to be searched and returned (e.g., pages, paragraphs, titles). Paragraphs are straightforward, since they are encoded as XML elements having the generic identifier $p$ :

\section{define(PARA,(ELEMENTS("p")))}

Titles are slightly more complicated: some titles are synthesized for the e-corpus, and so both they and their original print forms are tagged differently than section titles that are maintained without alterations, and the names of works in the corpus also use distinctive tags. As a result, for this corpus, titles are encoded as XML elements with any of four generic identifiers:

\section{define(TITLE,( (ELEMENTS("title") or ELEMENTS("synTitle") or ELEMENTS("printTitle") or ELEMENTS("origTitle")) ))}

Finally, because pages and columns are indicated by milestones only, their extents must be described as extending from one milestone (inclusive) to the next (exclusive):

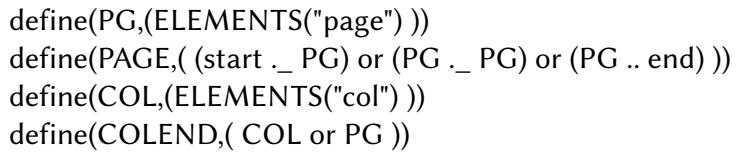

$$
\begin{aligned}
& \text { define(COLUMN,( (start ._COL) or } \\
& \quad(\mathrm{COL} \text {._ COLEND) or (COL .. end })))
\end{aligned}
$$

Similarly to identifying pages and columns based on such extents, the location text to be displayed for a match (as in Figure 3) can be constructed from the one found in the extent that is defined from the preceding location attribute, regardless of tag, (inclusive) to the location attribute that follows (exclusive).

In all, 26 sgrep rules are defined to support boolean search within any of six structures (paragraphs, titles, sentences, sections, pages, or columns) present in the Alberti Magni e-corpus and to support the searches needed to highlight matches and display the locations of the matched results.

With these rules defined, to find all paragraphs that contain the string "elicit", the search engine first identifies all paragraph regions $P$ that contain regions (of length 6) exactly matching the search string. It next finds all regions $M$ that exactly match the search string within regions in $P$. It then finds all regions $L$ that start at one location attribute and end with another and contain the start of the regions exactly matching the search string (i.e., the "e" of "elicit"). The search engine outputs the number of matching regions in $P$ and the number of matching regions in $M$. After that, for each region in $P$, it constructs the location identifier for the first location attribute in $L$ that falls within that region and prints the location followed by the contents of the matching paragraph from $P$, surrounding each word containing a match in $M$ with $<$ match $>$ and $</$ match $>$ to provide highlighting. Figure 4 shows the two paragraphs in the document "De sex principiis" that contain the three instances of words that include the string "elicit", each identified by the locations of those matches. Similar processing is applied when searching for phrases

\begin{tabular}{l|l|l|l|l|l||} 
Alberti Magni & \multicolumn{2}{c|}{ Colour Key } \\
E-Corpus & \begin{tabular}{|l|l|l|l|l} 
matched \\
text
\end{tabular} & $\begin{array}{l}\text { unedited } \\
\text { forms }\end{array}$ & $\begin{array}{l}\text { corrected } \\
\text { forms }\end{array}$ & $\begin{array}{l}\text { transliterated } \\
\text { Greek }\end{array}$ & $\begin{array}{l}\text { transliterated } \\
\text { Hebrew }\end{array}$ \\
\hline
\end{tabular}

Searching texts for exact matches (but ignoring capitalization)

2 (3) matches (instances) in De sex principiis (ed. Borgnet, 1890)

1. De sex principiis (ed. Borgnet, 1890), tract.1, cap.1, p.307a

Sicut autem et in aliis, sic et in his modus philosophiae tenendus est. Philosophi enim est (ut dicit Aristoteles) non accipere nisi sermonem demonstrativum, ut scilicet de subjecto et de partibus subjecti passiones et differentiae demonstrentur ad habendam notitiam perfectam de his quae traduntur : et ideo etiam singulorum diffinitiones ponendae sunt, ex quibus sicut ex mediis probetur omne quod docendum est. Hoc enim modo perficitur anima secundum partem contemplativam, quae est ultimum felicitatis ipsius, ut docet Aristoteles.

2. De sex principiis (ed. Borgnet, 1890), tract.3, cap.2, p.333a

Est autem passio de numero eorum quae multipliciter dicuntur. Animae enim actionum unaquaeque passio dicitur : quas tamen secundum intentionem praedicamenti actionis sub actione locamus, sicut est amor, et odium, et tristari, et gaudere, quae omnia passibiles actiones animae vocamus : haec enim omnia passiones sunt secundum quod a conceptis sunt illatae. Concepta enim vel concepta sunt ut bona, vel concepta sunt ut mala. Si ut bona sunt concepta, aut concepta sunt ut praesentia ad usum vel fructum, aut ut absentia. Si sunt concepta ut praesentia ad usum vel fructum, dilatatur ad illa cor et diffunditur spiritus, et effunditur cor per diastolem super illa : et sic est gaudium. Si autem concipitur ut non praesens : tunc ad ipsum dirigitur cor, et erigitur spiri-/333a/-tus, et fit passio quae spes vocatur. Si vero concipitur ut malum, ut contrarium : tunc iterum aut concipitur ut praesens et nocumentum inferens, aut ut futurum et expectatum. Si primo modo, tunc elicit passionem doloris vel tristitiae. Si autem concipitur ut futurum, tunc elicit passionem timoris. In omnibus his tamen agit anima fugiendo, vel se contrahendo, vel aperiendo, vel dilatando se ad usum vel expectationem.

Figure 4: Search for paragraphs containing "elicit” 
Table 1: Equivalences for orthographic normalization

$\begin{array}{cccccccccc}\text { ae } & \text { ci } & \text { d } & \text { j } & \text { k } & \text { m } & \text { oe } & \text { ph } & v & y \\ \text { e } & \text { ti } & \text { t } & \text { i } & c & n & \text { e } & f & u & i\end{array}$

(i.e., strings that include blanks, such as "quod equus et homo"), ${ }^{6}$ ordered words (e.g. "prima*secundum"), or boolean combinations of these (e.g., "dicit Aristoteles" + (bestia | animal | brut)).

Variations in Latin spelling, especially when the sources are varied, add a complication to search. For example, the letters $j$ and $i$ are often used interchangeably, as are the letter pairs $c i$ and $t i$; the letter $h$ is sometimes omitted and apostrophes are used inconsistently. To simplify search, therefore, the search engine includes an option for searching with normalized spelling, where the following rules are used for orthographic normalization: remove diacritics, ignore capitalization, ignore $h$ and apostrophe ('), use the equivalences in Table 1, and ignore repeated letters. Thus, for example, philosophiae is normalized as filosofie, Tyrrhenum is normalized as tirenun, and prooemio is normalized as prenio.

A complication arises from region-based search that is not present in word-based search. With exact match, a search for the string philosophia matches all instances of the prefix of philosophiae. However, philosophia is normalized as filosofia, so a search for its normalized form does not match the normalized form of instances of philosophiae. As a result, users may be surprised to learn that search under normalization can produce fewer results than search for the same string without normalization. To adjust for this anomaly, a normalized search for any string ending in a is similarly interpreted as searching also for that string ending in ae; a normalized search for any string ending in o is interpreted as searching also for that string ending in oe; a normalized search for any string ending in $\mathrm{c}$ is interpreted as searching also for that string ending in $\mathrm{ci}$; and a normalized search for any string ending in $\mathrm{p}$ is interpreted as searching also for that string ending in ph. This approach guarantees that no matches are missed, although some false positives might be returned, such as instances of the string ille when searching for strings matching illa (normalized).

Search engines based on inverted indexes (postings lists) typically support normalized search by incorporating orthographic normalization as part of text tokenization prior to indexing. However, because sgrep does not use an index, an alternative method is needed to search for normalized text. The solution is to build a "shadow" text $X$ for each document $D$ in which each word $w_{i}$ is replaced by its normalized form $n_{i}$, but the offset of $n_{i}$ in $X$ remains unchanged from the offset of $w_{i}$ in $D$. Subsequently a search for normalized query terms in $X$ returns a list of matching offsets. These offsets are then used to locate the corresponding instances of the unnormalized words in $D$. Figure 5 shows a partial result from a search with normalized spelling.

The indexing cost of this approach is the time to normalize all documents and an amount of space equal to the sum of the sizes of the original documents. For a corpus supporting research in the humanities, even one as large as the Alberti Magni e-corpus,

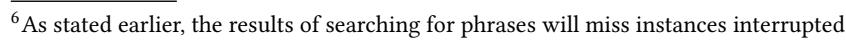
by tags.

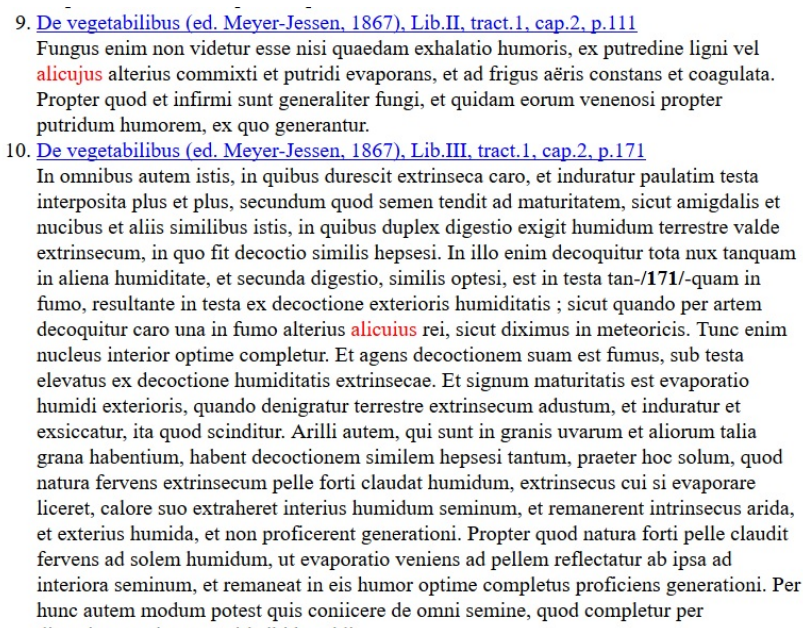

Figure 5: Search for "alicujus" with normalized spelling

this is quite manageable: it takes only a couple of seconds ${ }^{7}$ to create the $130 \mathrm{MB}$ normalized version of the Alberti Magni e-corpus. Because of the need to merge lists, the engine's response time for searching all sixty documents increases with normalization from 6 seconds (unnormalized) to 9 seconds (normalized) for a rarely occurring string (such as convertibilia), from 10 to 12 seconds for a frequently occurring string (such as illa), and from 13 seconds to 19 seconds for an extremely common string (such as a).

\section{DISPLAYING MATCHED TEXT}

After a search, the matching portions of a document need to be displayed, as illustrated in Figures 4 and 5. To this end, the Dragoman text display subsystem processes text sequentially, replacing simple XML opening and closing tags, attributes, and entity references by the text specified in a user-selected style sheet and chosen by the designer to reflect the structure of the text through typography. The result is then passed to an HTML renderer (i.e., a web browser) for display.

The style sheet dictates how to interpret tags, attributes, and entity references as they are encountered in a left-to-right traversal of the text to be displayed, transforming the string into HTML. An important characteristic of the formatter is that not only can tags, attributes, and entity references be replaced by formatting or other symbols, but they can also be used to suppress arbitrarily large portions of text. Optionally, a matched opening and closing tag pair or a tag's attribute can be interpreted to indicate that the text between the tags or the attribute's value be treated as if it were an entity reference (effectively interpreting the opening tag as the start of an entity reference and the closing tag as its end).

Each line of a style sheet has three tab-separated fields, and as each tag is encountered in the text to be displayed, Dragoman searches for a line in the style sheet matching the tag's tagID in the first field (the indicator):

\section{taglD action startText action endText}

${ }^{7}$ All reported performance statistics are based on single-threaded execution under Ubuntu 16.04 on a shared 2 CPU - Intel E5-2697 v3 Xeon machine with 256GB Ram. 


$\begin{array}{lll}+ & & \\ \% \% & & \\ \text { match } & "<\text { font color="red"> } & "<\text { font }> \\ \text { d:tract } & " & " \\ \text { d:tract.val } & " & "<\text { br/> } \\ \text { greek } & - & + \\ \% \% & & \\ \& \text { md; } & \text { "\&mdash; } & \end{array}$

Figure 6: Simple Dragoman style sheet

If the encountered tag is a start tag, the first of the two actions is activated, and if it is an end tag, the second is activated. Either or both startText and endText may be empty strings. If the onecharacter action is a quotation mark, the tag is replaced by the startText or endText, respectively, subject to print suppression; using a minus sign in place of the quotation mark dictates that printing of text be suppressed, a plus sign dictates that printing of text be restarted, an asterisk dictates that the replacement text be printed regardless of print suppression, and an ampersand dictates that the tag content be interpreted as if it were an entity reference. Except for the last of these actions, there is no reliance on tags in the text being properly matched. Tags not matching any indicator in the table are printed as text (subject to print suppression) by replacing the left angle bracket by \&lt; so that it is interpreted as character data rather than as a tag.

Attributes are handled similarly, except that attributes are identified by the indicator tagID.attrname; the actions (text replacement, print suppression, etc.) occur before and after the attribute value, respectively; and attributes not matching any indicator have their values suppressed by default. Entity references are also handled similarly to tags, except that there is only one action specified per indicator, and it must begin with a quotation mark to indicate text replacement.

A style sheet has the following structure:

- It begins with a plus or minus, signalling whether print is initially on or suppressed.

- After a line with two percent signs, it lists tags or attributes in arbitrary order, with a pair of actions specified for each.

- After another line with two percent signs, it lists entities in arbitrary order, with a single action specified for each

For the simple style sheet shown in Figure 6, printing is initially on, the content between match tags are displayed in red, $d$ : tract start and end tags are simply ignored (the tags are replaced by empty strings), a line break is inserted after printing the value of the attribute val on a d:tract tag, the printing of any content occurring between greek start and end tags (inclusive) is suppressed, and the entity reference \&md; is passed on to the HTML renderer as an entity reference, namely \&mdash;. All other tags and entity references are passed to the renderer as character data and any other attributes on the $d$ : tract and greek tags are ignored.

For the Alberti Magni e-corpus, style sheets were created to display matched text in an easily readable form, either before or after the light editing of the works. In addition, a style sheet was created to display text with all tags uninterpreted so that the exact structure is visible. Printing the same paragraph with each of these
Super Porphyrium De V universalibus (ed. Borgnet. 1890), tract.5. cap.1. p.82a Hoc autem quod dictum est manifestatur exemplariter : quia huic generi quod est animal, rationale adveniens in diffinitione hominis vel Dei facit id quod in substantia est alicujus aliud ab eo a quo differt per illam differentiam, facit enim rationale animal, et facit speciem subalternam animal. Illa vero quae est communiter differentia per id quod est causa differentiae, ut movendi quo differt aliquis a quiescente, non facit nisi alteratsmet non aliud, quantum est de eo quod est causa differentiae quod est separal e acdens. ncludit ergo quod quaedam differentiarum facit aliud secundum sub-/8207-stantiam, quaedam autem non facit nisi alteratum.

(a) unedited

Super Porphyrium De V universalibus (ed. Borgnet, 1890), tract.5, cap.1, p.82a Hoc autem quod dictum est manifestatur exemplariter : quia huic generi quod est animal, rationale adveniens in diffinitione hominis vel Dei facit id quod in substantia est alicujus aliud ab eo a quo differt per illam differentiam, facit enim rationale animal, et facit speciem subalternam animal. Illa vero quae est communiter differentia per id quod est causa differentiae, ut movendi quo differt aliquis a quiescente, non facit nisi alteratunon aliud, quantum est de eo quod est causa differentiae quod est separabi accidens. Ooncludit ergo quod quaedam differentiarum facit aliud secundum sub-rosurstantiam, quaedam autem non facit nisi alteratum. (b) edited

Super Porphyrium De V universalibus (ed. Borgnet. 1890), tract.5, cap.1. p.82a $\langle\mathrm{p}\rangle\langle\mathrm{s}\rangle$ Hoc autem quod dictum est $<$ match $>$ manifestatur exemplariter $</$ match $>$ : quia huic generi quod est animal, rationale adveniens in diffinitione hominis vel Dei facit id quod in substantia est alicujus aliud ab eo a quo differt per illam differentiam, facit enim rationale animal, et facit speciem subalternam animal. $\langle/ \mathrm{s}\rangle\langle\mathrm{s}\rangle$ Illa vero quae est communiter differentia per id quod est causa differentiae, ut movendi quo differt aliquis a quiescente, non facit nisi alteratum et non_alind_anantum est de eo quod est causa differentiae quod est separabil<corr w="acdens" $>$ accidens $</$ corr $>>$ s $>$ $<\mathrm{s}>$ Concludit ergo quod quaedam differentrartim factitatud secturdum $<$ frag $\mathrm{w}=$ "substantiam" $>$ sub $</$ frag $><$ col n="82b" loc="[; tract.5; cap.1; p.82b]"/> $<$ cont $>$ stantiam $</$ cont $>$, quaedam autem non facit nisi alteratum. $\langle/ \mathrm{s}\rangle\langle/ \mathrm{p}\rangle$

(c) show tags

\section{Figure 7: Display of text using three style sheets}

style sheets is shown in Figure 7. Two additional style sheets were created for displaying large portions of the documents. The first of these suppresses the printing of most text fields but preserves section headings and titles, with suitable inclusion of markup for unordered lists to display a text's structure, and displays a red asterisk for every match (so that each asterisk appears underneath the heading for the section within which the match occurs), as illustrated by the output fragment in Figure 8; in response to clicking on an asterisk, the system displays the text page on which the corresponding match occurs. The second additional style sheet preserves the single- and two-column formatting of the source texts, as shown in Figure 9.

Like LECTOR, on which it is based, DrAgOMAn uses a "best-effort" approach to interpreting markup. Unlike CSS [15], it does not rely on the tagged text conforming to well-formed XML in order to display text. Instead, any errors in markup are ignored, relying instead on the user's interpretation of the rendered display to discover errors in the input text or in the style sheet. This forgiving nature has repeatedly proven especially useful during periods in a project's life cycle in which the code for structure recognition (Section 3) is under development or undergoing change. 


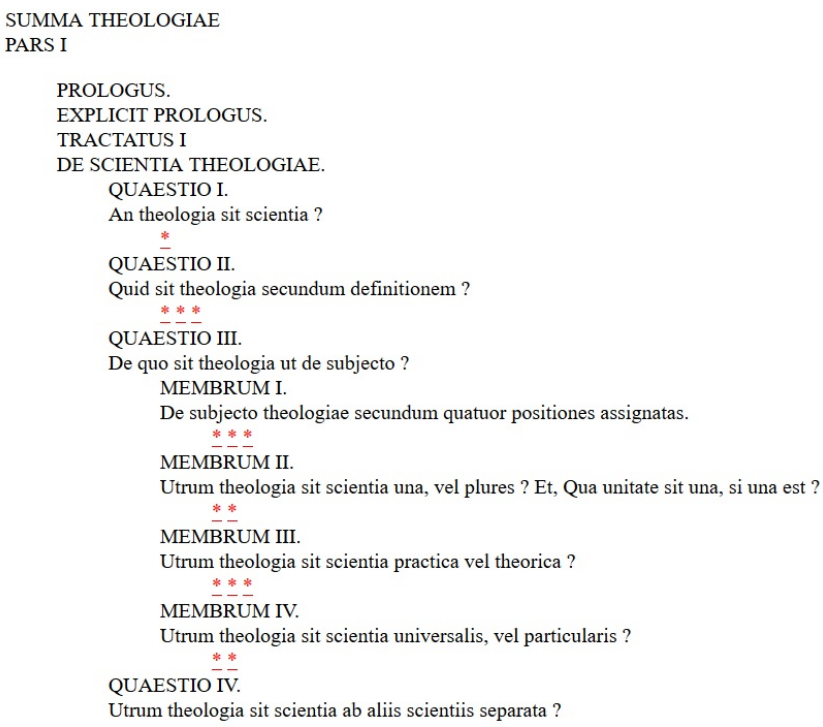

Figure 8: Search for "licit": Text suppression and hyperlink generation with a style sheet

Super lucam (1)

(ed. Borgnet, 1894)

/1/IN SACROSANCTA EVANGELIA LUCULENTA EXPOSITIO.

PROOEMIUM BEATI LUCAE IN EVANGELIUM SUUM.

1. Quoniam quidem multi conati sunt ordinare narrationem quae in nobis completae sunt rerum,

2. Sicut tradiderunt nobis qui ab initio ipsi viderunt, et ministri fuerunt sermonis:

3. Visum est et mihi, assecuto omnia a principio diligenter, ex ordine tibi scribere, optime Theophile.

4. Ut cognoscas eorum verborum, de quibus eruditus es, veritatem.

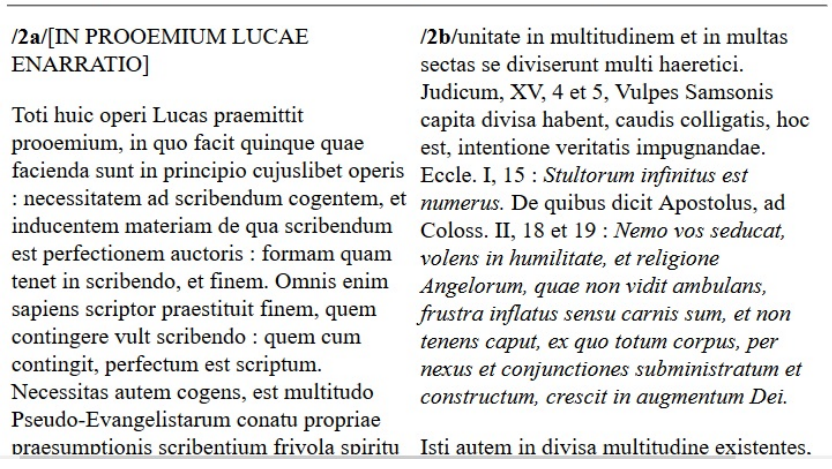

Figure 9: Using a style sheet that preserves columns

\section{RETROSPECTIVE AND FURTHER WORK}

With the ubiquity of search engines and web browsers, it may seem that all retrieval applications can be easily addressed with off-theshelf tools. However, scholars in the humanities have demanding needs for text search and display. Some of these have been addressed by the software developed for the Alberti Magni e-corpus project. $^{8}$ In particular, after preparing the scholar's texts in a suitable XML-tagged form, a system built on top of sgrep for search and DRAGOMAN for display can address many of those needs. ${ }^{9}$

Alternative XML-aware search engines (such as BaseX [20], eXist [21], Wumpus [3], or XQEngine [16]) could equally well have been used in this project, simplifying some solutions but requiring more effort to address other concerns. For example, using an XQuery engine with full-text search capability [12], would allow phrase searches across tags, thus eliminating the shortcoming in using sgrep when confronted by phrase instances that cross page and column breaks and across shifts to and from italic and bold text. However, because pages and columns form a hierarchical structure that is not nested with respect to logical text structures from books and chapters down to paragraphs and sentences, it is necessary to use milestone tags; thus searching within pages or columns or displaying the contents of a single page or column is less convenient with XQuery than it is with sgrep. ${ }^{10}$ No matter which engine is chosen, code must be implemented to address the normalization of Latin orthography, and for word-based (as opposed to region-based) systems, Latin-specific stemming rules must be implemented.

In retrospect, would it have been preferable to use XQuery in place of sgrep to serve as the query language for building a search engine for the Alberti Magni e-corpus? Because XQuery is defined by a suite of $\mathrm{W} 3 \mathrm{C}$ recommendations [33], adopting that language provides the option of choosing among several well-maintained software implementations and the likelihood that such software will continue to be available for the foreseeable future. XQuery is a far more powerful language than sgrep, which is restricted to identifying and extracting regions from a document in the order that they appear. The computational power of sgrep is therefore more similar to XPath Version 1.0 [4] (but with the addition of intersection and difference of sets and not being restricted to XML) than it is to XQuery. However, the needs of the scholars wishing to access the Alberti Magni e-corpus are for a simple query interface that finds regions of text from a collection of documents and presents matches to queries in the order that they appear in those documents, and this computational requirement does not require the expressive power of XQuery. Were a similar project to re-start today, serious consideration should be given to building the engine with software that supports XPath Version 3.0 or XQuery, but using a simple region algebra such as the one supported by sgrep (or Wumpus, if the corpus is large enough to require an index) should also receive due consideration. The amount of implementation effort to connect the user interface to the search software is likely to be quite similar for both approaches.

Converting matched text from XML to an HTML display form can also be implemented using XML technology based on W3C recommendations, namely CSS [15]. As is true for search, the needs for

\footnotetext{
${ }^{8}$ The software is freely available at https://github.com/fwtompa/e-corpusSE.

${ }^{9}$ One scholar recently wrote: "I am using the engine a lot these days for my research, and it is extraordinarily useful to me." Another posted the comment: "The Alberti Magni E-Corpus ... [has] some very nice search features. (Which is important, because Google Books is sometimes really crazy about its word recognition in modern languages, much less in Latin.)" A web site states: "l'opera di Alberto Magno scaricabile in formato pdf e, soprattutto, liberamente ricercabile on line ... si tratta di uno strumento che avrà ancora per molti una sua utilità."

${ }^{10}$ See https://wiki.tei-c.org/index.php/Milestone-chunk.xquery for a solution in XQuery, implemented as util:get-fragment-between in eXist.
} 
the Alberti Magni e-corpus do not require the computational power of general transformations. Instead, DraGoman uses only a simple tag interpretation algorithm that is easily explained. The tasks of writing several style sheets and controlling which style sheet to invoke is required, regardless of the implementation technology.

The most difficult part of starting a project with a new corpus is to convert the text into XML that reflects its logical structure, an extremely challenging task when physical layout must be interpreted [8], but also quite challenging when the input is plain text with embedded font information. ${ }^{11}$ In most of the text, each feature to be tagged can be recognized fairly easily, but unexpected difficulties arise when the features overlap in unanticipated ways. These problems do not result from the choice of software, but rather they are inherent in working with human-generated data: regardless of the approach taken to recognize structure, every form of feature interleaving that appears in the corpus must be accommodated by the conversion system. In several projects, we have successfully written converters that process the input sequentially in multiple passes. An alternative approach worthy of investigation is to drive the recognition process by a grammar that reflects the structures to be recognized. Unfortunately, developing such grammars for documents that have not yet been transformed into XML may be an equally challenging task due to the presence of many unanticipated exceptions that are commonly present in documents that were written over decades using just pen and paper [34]. Based on his experiences during several projects, Cummings has similarly observed:

"The process of using an incremental ad hoc intermediate format is quite common in such conversions. In many cases it is difficult to know very much about the structure of the document until much of the conversion has been done, hence an incremental approach allows a greater ease of recovery from mistaken conversion steps. However, it highlights a basic problem in such attempts to manipulate legacy files: that until they are in some format for which tools exist, it is difficult to examine or validate their structure." [6]

The specific tag set chosen for the Alberti Magni e-corpus can be improved. It has several idiosyncratic aspects, such as the chosen division names (Figure 2) and the use of $\langle$ frag $>$ and $<$ cont $>$ tags to represent words split across page and column breaks. If the scholars responsible for managing the e-corpus wish to share the tagged documents with other scholars, they will be well-served to first transform the tagging to be TEI-compliant [29]. Because the corpus has already been structured as well-formed XML, this should be far simpler than applying tags to a new document, and standard XML transformation tools, such as XSLT [17], can surely be used without difficulty. Thereafter, it may be worthwhile to develop a DTD [24] or XSD [22, 25] schema that describes the constraints on document structures found in the collection.

When the Alberti Magni e-corpus project was started, it was intended that the software should be easily applied to any scholar's

\footnotetext{
${ }^{11}$ The XML tags that are output by today's OCR readers often represent physical properties of the text only, such as columns and typefaces. However, more sophisticated document analysis can also be applied to capture logical structure [13].
}

corpus with minimal customization. Both sgrep and DRAGOMAN provide simple mechanisms for adapting the search and display to new corpora. Therefore, the system could easily be used by scholars who work with other document collections. However, the functionality that is provided by the code base that ties these two components together with the query interface is specific to the needs of the Albertus Magnus scholars: the various modes of search, the requirement to display snippets with location information, and the ability to browse documents at most one page at a time may not fulfill all the needs of other scholars. For example, the software provides no ability to rank results, no ability to pose a query in which some terms use normalized spellings and others do not, no ability to compare two documents directly (e.g., to find similar passages, to analyze text differences, or to examine primary and secondary sources together), no ability to link a passage in a document to its critical apparatus (except by proximity), no ability to attach new annotations to a document, and so forth. A more widely acceptable scholars' search engine still requires much work.

\section{ACKNOWLEDGMENTS}

User requirements for the software were developed in consultation with University of Waterloo Professors Delbert Russell (for Campsey) and Bruno Tremblay (for Albertus). The implementation benefitted from assistance with earlier versions from two (then undergraduate) students: Jingchi (Evan) Chen (January 2004-April 2004 for the Camsey project) and Shadab Ul Rashid (May 2008December 2008 for the Alberti Magni e-corpus project) and from repeated discussions with Andrew Kane, who also provided valuable feedback to improve this paper. Facilities were provided by the University of Waterloo, and financial support for the students was provided by NSERC, the Natural Sciences and Engineering Research Council of Canada, and by CFI, the Canada Foundation for Innovation.

\section{REFERENCES}

[1] David M. Berry. 2011. The computational turn: Thinking about the digital humanities. Culture Machine 12 (2011), 1-22.

[2] Chris Biemann, Gregory R Crane, Christiane D Fellbaum, and Alexander Mehler. 2014. Computational Humanities-Bridging the gap between Computer Science and Digital Humanities (Dagstuhl Seminar 14301). Dagstuhl Reports 4, 7 (2014), 80-111.

[3] Stefan Büttcher. 2018. Wumpus File System Search. http://www.wumpussearch.org/. (accessed April 2018).

[4] James Clark and Steven DeRose. 1999. XML Path Language (XPath) Version 1.0. W3C Recommendation. W3C. http://www.w3.org/TR/1999/REC-xpath-19991116.

[5] Mariano P Consens and Tova Milo. 1998. Algebras for querying text regions: Expressive power and optimization. f. Comput. System Sci. 57, 3 (1998), 272-288.

[6] James Cummings. 2006. Liturgy, drama, and the archive: Three conversions from legacy formats to TEI XML. Digital Medievalist 2 (2006)

[7] James Cummings. 2008. The Text Encoding Initiative and the Study of Literature. In A Companion to Digital Literary Studies, Susan Schreibman and Ray Siemens (Eds.). Blackwell, Chapter 25, 451-476.

[8] Andreas Dengel and Faisal Shafait. 2014. Analysis of the Logical Layout of Documents. In Handbook of Document Image Processing and Recognition, David Doermann and Karl Tombre (Eds.). Springer, Chapter 6, 177-222.

[9] Charles N Fischer, Ronald K Cytron, and Richard J LeBlanc. 2009. Crafting a Compiler. Addison-Wesley, Chapter 6, 179-234.

[10] Gaston H. Gonnet. 1987. PAT 3.1: An Efficient Text Searching System. User's Manual. Center for the New Oxford English Dictionary. University of Waterloo, Waterloo, Canada.

[11] Gaston H. Gonnet, Ricardo A. Baeza-Yates, and Tim Snider. 1992. New Indices for Text: PAT Trees and PAT Arrays. In Information Retrieval: Data Structures \& Algorithms, William B. Frakes and Ricardo A. Baeza-Yates (Eds.). Prentice Hall, Chapter 5, 66-82. 
[12] Christian Grün, Sebastian Gath, Alexander Holupirek, and Marc H. Scholl. 2009 XQuery full text implementation in BaseX. In Database and XML Technologies 6th International XML Database Symposium (XSym 2009). Springer, 114-128.

[13] Yasuto Ishitani. 2003. Document transformation system from papers to XML data based on pivot XML document method. In 7th International Conference on Document Analysis and Recognition (ICDAR 2003). 250-255.

[14] Jani Jaakkola and Pekka Kilpeläinen. 2018. Sgrep home page https://www.cs.helsinki.fi/u/jjaakkol/sgrep.html. (accessed April 2018).

[15] Tab Atkins Jr., Elika Etemad, and Florian Rivoal. 2017. CSS Snapshot 2017. W3C Note. W3C. https://www.w3.org/TR/2017/NOTE-css-2017-20170131/.

[16] Howard Katz. 2018. XQEngine at SourceForge. http://xqengine.sourceforge.net/. (accessed April 2018)

[17] Michael Kay. 2017. XSL Transformations (XSLT) Version 3.0. W3C Recommendation. W3C. https://www.w3.org/TR/2017/REC-xslt-30-20170608/.

[18] Rick Kazman. 1986. Structuring the Text of the Oxford English Dictionary through Finite State Transduction. (1986). MMath Thesis, Department of Computer Science, University of Waterloo, Technical Report CS-86-20.

[19] Tibor Kiss and Jan Strunk. 2006. Unsupervised multilingual sentence boundary detection. Computational Linguistics 32, 4 (2006), 485-525.

[20] Cerstin Mahlow, Christian Grün, Alexander Holupirek, and Marc H. Scholl. 2012 A framework for retrieval and annotation in digital humanities using XQuery full text and update in BaseX. In ACM Symposium on Document Engineering (DocEng2012). 195-204.

[21] Wolfgang Meier. 2002. eXist: an open source native XML database. In Web, WebServices, and Database Systems: NODe 2002 Web and Database-Related Workshops, Revised Papers. Springer, 169-183.

[22] Noah Mendelsohn, Michael Sperberg-McQueen, Murray Maloney, David Beech, Sandy Gao, and Henry Thompson. 2012. W3C XML Schema Definition Language (XSD) 1.1 Part 1: Structures. W3C Recommendation. W3C. http://www.w3.org/TR/2012/REC-xmlschema11-1-20120405/.
[23] Anoop M Namboodiri and Anil K Jain. 2007. Document Structure and Layout Analysis. In Digital Document Processing. Springer, 29-48.

[24] Jean Paoli, François Yergeau, Michael Sperberg-McQueen, Tim Bray, and Eve Maler. 2008. Extensible Markup Language (XML) 1.0 (Fifth Edition). W3C Recommendation. W3C. http://www.w3.org/TR/2008/REC-xml-20081126/.

[25] David Peterson, Ashok Malhotra, Michael Sperberg-McQueen, Henry Thompson, Paul V. Biron, and Sandy Gao. 2012. W3C XML Schema Definition Language (XSD) 1.1 Part 2: Datatypes. W3C Recommendation. W3C. http://www.w3.org/TR/2012/REC-xmlschema11-2-20120405/.

[26] Darrell R. Raymond. 1992. Flexible Text Display with Lector. IEEE Computer 25, 8 (1992), 49-60.

[27] Irven Resnick (Ed.). 2013. A Companion to Albert the Great: Theology, Philosophy, and the Sciences. Brill.

[28] Airi Salminen and Frank Wm. Tompa. 1992. PAт expressions: an algebra for text search. Acta Linguistica Hungarica 41, 1-4 (1992), 277-306.

[29] TEI Consortium (Ed.). 2018. TEI P5: Guidelines for Electronic Text Encoding and Interchange. TEI Consortium. http://www.tei-c.org/Guidelines/P5/ Version 3.3.0, Last updated on 31st January 2018.

[30] Frank Wm. Tompa. 1992. An overview of Waterloo's database software for the OED. In Proc. Symp. on Historical Dictionary Databases and Data Retrieval Requirements (Centre for Computing in the Humanities Working Papers 2). University of Toronto, 123-143.

[31] Elaine G. Toms and Heather L. O'Brien. 2008. Understanding the information and communication technology needs of the e-humanist. Fournal of Documentation 64, 1 (2008), 102-130.

[32] Bruno Tremblay. 2018. Alberti Magni e-corpus. http://albertusmagnus.uwaterloo .ca/. (accessed April 2018).

[33] World Wide Web Consortium (W3C). 2018. XML Technology. https://www.w3.org/standards/xml/. (accessed April 2018)

[34] Matthew Young-Lai and Frank Wm. Tompa. 2000. Stochastic Grammatical Inference of Text Database Structure. Machine Learning 40, 2 (2000), 111-137. 